\title{
La Organización Mundial de Comercio, los acuerdos mega-regionales y los usos estratégicos del regionalismo
}

\author{
ROBERTO BOUZAS ${ }^{\text {a }}$, JULIETA ZELICOVICH ${ }^{\text {b }}$ \\ a Consejo Nacional de Investigaciones Científicas y Técnicas, CONICET, Universidad de San \\ Andrés, Vito Dumas 284, VB1644BID Victoria (Pcia. de Buenos Aires), Argentina. E-mail: \\ rbouzas@udesa.edu.ar \\ ${ }^{b}$ Universidad Nacional de Rosario, Facultad de Ciencia Política y Relaciones Internacionales, \\ Riobamba 250 Bis. Monoblock $N^{o}$ 1, 2000EKF Rosario, Santa Fe, Argentina. E-mail: \\ julieta.zelicovich@fcpolit.unr.edu.ar
}

\section{RESUMEN}

La parálisis de la Ronda Doha, el desarrollo de grandes negociaciones "mega-regionales" y la proliferación de acuerdos preferenciales han avivado los debates sobre la gobernanza del comercio internacional. Mientras que una interpretación benévola sobre estos acuerdos parece estar ganando lugar, en este artículo sostenemos que los atributos del "regionalismo del siglo XXI" son menos novedosos que lo que se insinúa; y que existe una notable continuidad en los incentivos y las características del "nuevo regionalismo" de los noventa y el llamado "regionalismo del siglo XXI". Afirmamos que aun cuando los componentes discriminatorios de estos regionalismos hayan sido atenuados por el contenido y naturaleza de la agenda regulatoria, el conflicto básico entre las dos modalidades de gobernanza del régimen de comercio internacional sigue vigente.

Palabras clave: Acuerdos comerciales internacionales, integración económica, comercio.

\section{The World Trade Organization, Mega-Regional Trade Agreements and the Strategic Uses of Regionalism}

\begin{abstract}
The paralysis of the Doha Round, the proliferation of preferential trade agreement and the launching of mega-regional trade negotiations have encouraged the debate about the governance of international trade. In contrast to a benign interpretation of the relationship between "XXI century regionalism" and the multilateral trade regime, we argue that there is a remarkable continuity between the incentives and characteristics of the "new regionalism" and those of "XXI century regionalism". Even when the content of the regulatory agenda may have reduced the discriminatory nature of the new agreements, the basic conflict between the two modalities of governance of the international trade regime remains in place.
\end{abstract}

Keywords: International Trade Agreements, Economic Integration, Trade.

Clasificación JEL: F13, F15, F59

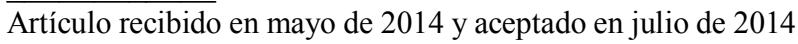

Artículo disponible en versión electrónica en la página www.revista-eea.net, ref. ə-32313

ISSN 1697-5731 (online) - ISSN 1133-3197 (print) 


\section{INTRODUCCIÓN}

El vínculo entre el régimen multilateral y los acuerdos preferenciales de comercio ha sido objeto de debate por alrededor de tres décadas. Este interés fue el resultado de dos fenómenos simultáneos. Por un lado, la explosión en el número de acuerdos preferenciales. Por el otro, la creciente ineficacia de la Organización Mundial de Comercio (OMC) en su papel como foro de negociación. A lo largo de este período el contenido del debate experimentó cambios sustanciales: se avanzó en la comprensión de los obstáculos estructurales que enfrenta el régimen multilateral en el ejercicio de su función como foro de negociación y se clarificaron algunas de las características distintivas de la nueva ola de acuerdos preferenciales que se inició a mediados de la década del ochenta. No obstante, las conclusiones sobre la naturaleza de ese vínculo siguen siendo materia de disputa.

Con base en este debate el artículo desarrolla dos argumentos principales. El primero es que el "nuevo regionalismo" que emergió con fuerza a mediados de los ochenta comparte muchas características (tanto en lo que hace al contenido de la agenda como a los incentivos de los principales actores) con el llamado "regionalismo del siglo XXI". El segundo es un corolario del anterior: aún cuando los componentes discriminatorios del "regionalismo del siglo XXI" hayan sido atenuados por el contenido de la agenda regulatoria, la tensión básica entre las dos modalidades de gobernanza del régimen de comercio internacional sigue vigente. En efecto, la evidencia y los argumentos en que se apoya el diagnóstico benévolo que sostiene la complementariedad entre el "regionalismo del siglo XXI" y la OMC son poco convincentes. En este artículo argumentamos que el vínculo entre ambas modalidades de gobernanza del sistema de comercio internacional sigue siendo esencialmente competitivo y que la extensión en el uso del regionalismo (especialmente por la diplomacia comercial norteamericana) ha tenido un sentido eminentemente estratégico. El lanzamiento de nuevas negociaciones mega-regionales confirma esta dirección.

El artículo está organizado en cinco secciones. En la primera se identifican los principales factores que explican la parálisis del régimen multilateral de comercio en su función como foro de negociación. En la segunda sección se revisan algunas propuestas de reforma institucional cuyo propósito es revitalizar el rol de la OMC como foro de negociación. La tercera sección resume la evolución del regionalismo en las últimas tres décadas, subrayando los elementos de continuidad por sobre los de cambio y el sentido estratégico que ha adquirido, especialmente para la diplomacia comercial norteamericana. La cuarta sección analiza los principales rasgos y obstáculos que enfrentan los llamados "mega-acuerdos regionales" que han comenzado a negociarse en los últimos años. Finalmente, cierra el artículo una sección de conclusiones. 


\section{EL BLOQUEO DE LA NEGOCIACION MULTILATERAL}

El fin de la Ronda Uruguay (RU) y la creación de la Organización Mundial de Comercio (OMC) marcaron el apogeo del entusiasmo en torno al potencial del multilateralismo como mecanismo de regulación del sistema de comercio internacional. La firma de dos nuevos acuerdos (sobre "comercio de servicios" y sobre derechos de la propiedad intelectual relacionados con el comercio), la puesta en marcha de un mecanismo más potente de solución de controversias y la mayor institucionalización que representó la creación de la $\mathrm{OMC}$ alentaron un diagnóstico positivo sobre la vitalidad y las perspectivas del multilateralismo. De igual modo se interpretó el lanzamiento de una nueva y ambiciosa ronda de negociaciones de Doha en noviembre de 2001, ampulosamente bautizada como Ronda del Desarrollo (RD). Este optimismo, sin embargo, pasaba por alto transformaciones estructurales cuyas consecuencias ya se habían puesto de manifiesto durante las negociaciones de la RU y que terminarían por dominar los trece años de negociaciones todavía inconclusas de la RD. ${ }^{1}$

La literatura muestra bastante consenso acerca de las principales transformaciones estructurales que afectaron la eficacia del régimen multilateral de comercio como foro de negociación. Entre ellas se destaca el cambio en la naturaleza de la agenda de negociación, la membresía más numerosa y heterogénea, las alteraciones en la influencia relativa de las coaliciones domésticas interesadas en temas de comercio (especialmente en los países desarrollados) y la emergencia de nuevos actores transnacionales organizados con intereses en el campo de la política comercial. ${ }^{2}$ Paradójicamente, muchas de estas transformaciones fueron consecuencia del propio éxito del Acuerdo General sobre Aranceles y Comercio (GATT) en la reducción de las barreras fronterizas al comercio y en el establecimiento de "códigos de conducta" que dieran estabilidad y certidumbre a las prácticas comerciales nacionales a lo largo de sus primeras cuatro décadas de existencia. Este marco regulatorio contribuyó a crear vínculos más estrechos entre las economías nacionales y a estimular la incorporación de nuevos miembros a un régimen en constante expansión. ${ }^{3}$

\footnotetext{
${ }^{1}$ En diciembre de 2013 en la reunión ministerial de Bali los miembros de la OMC aprobaron un nuevo acuerdo sobre facilitación del comercio. Este acuerdo es poco significativo cuando se lo compara con los objetivos del mandato original de negociación de la Ronda de Doha.

${ }^{2}$ Véase, por ejemplo, Barton et al. (2006), Warwick Commission (2007), Wilkinson (2006) y Ha-le et al. (2013).

${ }^{3}$ Según Rose (2004) el GATT no estimuló un comercio más intenso entre los miembros del régimen. No obstante, Subramanian y Wei (2007) y Tomsz et al. (2007) argumentan que la evidencia que presenta Rose no es robusta. En cualquier caso resulta difícil explicar la persistente expansión en la membresía del GATT sin alguna percepción de ganancia por parte de sus miembros (aún si ésta no se reflejara en más comercio).
} 
Los resultados obtenidos en materia de reducción de aranceles y otras barreras fronterizas al comercio pusieron en la agenda otras disciplinas (muchas de ellas de naturaleza no-fronteriza) cuya negociación resultó más conflictiva y cuya regulación dio lugar a una mayor intrusión en prácticas nacionales tradicionalmente no sujetas a la supervisión internacional. Paralelamente, la ampliación de la membresía se tradujo en la incorporación de nuevos países que transformaron un "club" relativamente selecto de naciones con visiones e intereses convergentes en un agrupamiento mucho más numeroso y heterogéneo. Con el correr del tiempo la tradicional hegemonía de la "alianza atlántica" también comenzó a mostrar signos de resquebrajamiento, producto de la diferenciación de intereses entre sus miembros y de la emergencia de nuevos actores influyentes en el escenario internacional. La multiplicación de actores no se limitó al ámbito de los Estados: distintos grupos organizados de la sociedad civil también comenzaron a tener una participación más activa en el debate sobre las políticas de comercio internacional. Así, lo que tradicionalmente había sido un terreno reservado al accionar del sector privado corporativo asistió al ingreso de nuevos actores con intereses diversificados. Cambios igualmente significativos tuvieron lugar en el plano doméstico, donde se alteraron la composición y el peso relativo de las coaliciones a favor y en contra de la protección.

Aunque estas transformaciones se aceleraron en las últimas dos décadas, la mayoría de ellas (así como sus consecuencias) ya eran visibles desde el comienzo de la RU. ${ }^{4}$ Un ejemplo de ello es la ampliación de la agenda de negociación hacia temas de naturaleza no-fronteriza: en efecto, sólo después de varios intentos frustrados se pudo alcanzar una fórmula de compromiso sobre el mandato para lanzar una nueva ronda de negociaciones en Punta del Este en 1986. Esta fórmula puso a las negociaciones sobre "comercio de servicios" en un compartimiento diferente al resto de los temas cubiertos por el GATT y separó el progreso de las negociaciones sobre protección de la propiedad intelectual e inversiones de los avances en el resto de la agenda acordada en Punta del Este (Croome, 1998: 24). Si bien estos "nuevos temas" se cristalizaron en dos nuevos acuerdos sobre "comercio de servicios" (Acuerdo General sobre Comercio de Servicios -AGCS-) y protección de la propiedad intelectual (Acuerdo sobre Derechos de la Propiedad Intelectual relacionados con el Comercio -ADPIC), en otros tópicos sensibles como el tratamiento de la inversión hubo poco avance. ${ }^{5} \mathrm{Si}$ bien el acta final de la RU también incluyó

\footnotetext{
${ }^{4}$ Las primeras manifestaciones pueden incluso rastrearse a la Ronda Tokio en la década del setenta, cuando se negociaron "códigos" de participación voluntaria en temas en los que existían bloqueos para alcanzar acuerdos que incluyeran a todos los miembros.

${ }^{5}$ El Acuerdo sobre Medidas en materia de Inversiones Relacionadas con el Comercio (MIC) fue un sustituto muy imperfecto del acuerdo sobre inversiones al que originalmente aspiraban algunos miembros del GATT, especialmente Estados Unidos. La sensibilidad del tema entre los
} 
temas en los que muchos países en desarrollo tenían intereses ofensivos (como la extensión de las reglas del GATT al comercio de productos agrícolas de clima templado o el progresivo desmantelamiento de las restricciones cuantitativas al comercio de productos textiles y de vestido), el acuerdo final sólo fue posible gracias a un tour de force en el que el principio del single undertaking (bajo el que se había negociado la RU) desempeñó un papel clave. ${ }^{6}$

Poco después de concluida la Ronda Uruguay la presión de algunos miembros por la ampliación de la agenda de negociación volvió a ponerse de manifiesto en los llamados "temas de Singapur". A partir de 1996 éstos tomaron forma en la creación de tres nuevos grupos de trabajo (sobre comercio e inversiones, política de competencia y transparencia en la contratación pública) y en el establecimiento de un mecanismo para explorar formas de simplificar los procedimientos comerciales (la llamada "facilitación del comercio"). ${ }^{7}$ En noviembre de 2001, no obstante el fracaso de la reunión ministerial de Seattle dos años antes y de los disturbios que la acompañaron, se lanzó una nueva ronda de negociaciones con una agenda ambiciosa, ampulosamente denominada "Ronda del Desarrollo". No hay duda que el ataque terrorista a las Torres Gemelas ese mismo mes y el shock que produjo en la comunidad internacional constituyó un fuerte estímulo para concluir la reunión ministerial de Doha con una nota positiva, en lugar de una nueva postergación.

Si bien los "temas de Singapur" fueron incorporados al mandato negociador de Doha, las modalidades de negociación (el ingrediente clave para dar contenido sustantivo al ejercicio) quedaron sujetas a un acuerdo explícito a realizarse en una fecha posterior. ${ }^{8}$ A poco de andar los límites para alcanzar ese acuerdo quedaron en evidencia: en efecto, tras la suspensión anticipada de las negocia-

propios países desarrollados ya se había puesto de manifiesto con el fracaso de las negociaciones para firmar un Acuerdo Multilateral de Inversiones (MIA) llevadas adelante en el marco de la OCDE entre 1995 y 1998. No obstante, y a diferencia del GATT, el AGCS incluyó el trato a la inversión dentro de las listas de compromisos de los miembros a través del llamado "modo 3" de abastecimiento (presencia comercial).

${ }^{6}$ Según el principio de single undertaking ningún acuerdo podía cerrarse hasta que todos los componentes del paquete estuvieran concluidos. Su aplicación práctica en las negociaciones de la RU implicó que, dado que el GATT 1947 sería reemplazado por un nuevo instrumento (el GATT 1994), aquellos países que no adhirieran al Acta de Marrakesh correrían el riesgo de perder las concesiones obtenidas en negociaciones previas. El resultado fue que incluso los países más renuentes debieron aceptar el paquete terminado de cerrar por Estados Unidos y la Unión Europea en el acuerdo de Blair House en 1992.

${ }^{7}$ Los "temas de Singapur" recibieron esa denominación porque fueron incluidos en la agenda de la OMC en la Conferencia Ministerial que se celebró en esa ciudad en el año 1996.

${ }^{8}$ Además de los temas tradicionales de aranceles y normas, servicios y propiedad intelectual, y de los temas Singapur, el paquete de Doha también incluyó los temas de comercio y medio ambiente, comercio electrónico y pequeñas economías, para los que se crearon sendos programas de trabajo. 
ciones en la Conferencia Ministerial de Cancún en el año 2003, los miembros decidieron en el año 2004 abandonar tres de los cuatro temas de Singapur (relación entre inversión y comercio, vínculo entre la política comercial y de competencia y transparencia en compras públicas). Finalmente sólo nueve años más tarde, en la reunión ministerial de Bali, los miembros de la OMC alcanzaron un acuerdo en el único "nuevo tema" con negociaciones todavía abiertas (facilitación del comercio). Este logro empalidece cuando se considera que la Ronda de Doha tampoco produjo resultados en temas de la agenda convencional, como el disciplinamiento de las ayudas internas a la agricultura, las salvaguardias o la protección arancelaria para el sector industrial que aplican algunos países en desarrollo. En efecto, estos temas tradicionales fueron el leit motiv de las sucesivas marchas y contramarchas experimentadas por las negociaciones desde 2006 en adelante.

La ampliación de la agenda de negociación hacia temas más conflictivos en el marco de una membresía más heterogénea no fue, sin embargo, el único cambio estructural por el que atravesó el régimen de comercio internacional en las últimas décadas. En efecto, la tradicional hegemonía de la "alianza atlántica" (fortalecida con la participación de Japón en lo que se llamó el "Quad") también comenzó a resquebrajarse, producto de la diferenciación de intereses entre sus miembros y de la emergencia de otros actores influyentes en el escenario internacional. ${ }^{9}$ Algunos países en desarrollo de mayor tamaño relativo como Brasil, la India y China expandieron su influencia y se convirtieron en "actores de veto" en un contexto político e institucional más contestado. La interacción de un número mayor de actores con capacidad de influencia (o veto) también redujo la efectividad de la combinación de reglas y ejercicio del poder que había estado en la base del funcionamiento del régimen multilateral durante la mayor parte del período de posguerra. ${ }^{10}$

Además de multiplicarse el número de actores estatales involucrados en las negociaciones también se alteró el equilibrio entre las coaliciones domésticas interesadas en la evolución y las regulaciones del régimen multilateral. Frente a los avances logrados en la liberalización arancelaria en la mayoría de los sectores industriales relevantes para los países desarrollados ${ }^{11}$, los nuevos intereses

\footnotetext{
${ }^{9}$ Según Wilkinson (2006) la primacía de la "alianza atlántica" había sido el mecanismo clave de articulación de los acuerdos, los que se extendían al resto de la membresía a través de la aplicación de los principios de reciprocidad y nación más favorecida.

${ }^{10}$ Barton et al. (2006) muestran persuasivamente como la combinación de la regla del consenso y el ejercicio del poder en momentos clave de las negociaciones permitieron que el régimen multilateral tuviera, simultáneamente, legitimidad y resultados sesgados hacia las preferencias de los miembros con mayor influencia.

${ }^{11}$ Un tema convencional en el que los países desarrollados presionaron con insistencia durante la Ronda de Doha fue la reducción de la protección arancelaria a los bienes industriales en los países en desarrollo. Estas demandas fueron fuertemente resistidas por el NAMA-11 (Argen-
} 
"ofensivos" progresivamente tomaron forma en áreas diferentes al comercio de bienes, siendo que los temas regulatorios (de carácter no-fronterizo) adquirieron una relevancia especial. Los obstáculos crecientes para traducir esta agenda en acuerdos multilaterales efectivos redujo su interés en ese foro y promovió un desplazamiento de energías y recursos hacia otras modalidades de negociación. Mientras los "intereses ofensivos" (típicamente asociados a la liberalización) encontraban canales más expeditos para traducir sus demandas en compromisos internacionales, la agudización de la competencia internacional en sectores tradicionales como consecuencia de la emergencia de nuevos países exportadores dinámicos (particularmente China) agravó las presiones proteccionistas domésticas y puso al régimen internacional en la mira de actores bien organizados. Estos cambios en el balance de influencia de los intereses domésticos se complementaron con la constitución de nuevos actores colectivos transnacionales que desarrollaron sus propias agendas con relación a la evolución del régimen multilateral de comercio. ${ }^{12}$

La sumatoria de estas transformaciones y la ausencia de resultados sustantivos en la Ronda de Doha después de más de una década de negociaciones abrió la puerta a un período de generalizado pesimismo sobre la eficacia y la funcionalidad del régimen multilateral. ${ }^{13}$ En los últimos años este pesimismo se reforzó con la idea de que la propia agenda de negociaciones acordada en Doha ya se había vuelto obsoleta y crecientemente irrelevante frente a los "temas comerciales del futuro". ${ }^{14}$ Según algunos autores la Agenda para el Desarrollo de Doha reúne una lista de temas acordados hace más de una década e identificados originalmente durante la RU, hace ya más de veinte años, los que ya tendrían pocos vínculos con las demandas funcionales planteadas por el sistema de comercio internacional del próximo cuarto de siglo (Baldwin y Evenett, 2011).

tina, Brasil, Sudáfrica, India, Venezuela, Egipto, Túnez, Filipinas, Indonesia y Namibia). China no integró esta coalición porque la protección arancelaria al sector industrial ya era baja como resultado de sus negociaciones de accesión.

${ }^{12}$ La emergencia de actores y coaliciones interesadas en la relación entre comercio y medio ambiente o comercio y mercado de trabajo es un ejemplo de ello.

${ }^{13}$ Cabe señalar que las crecientes dificultades en el ejercicio de la función negociadora de la OMC se produjeron a la par del incremento/fortalecimiento del papel de la institución en materia de promoción de la transparencia, la solución de controversias e incluso una reversión hacia políticas más abiertamente proteccionistas. Si bien es difícil constatar un argumento contrafáctico, hay alguna evidencia de que los compromisos asumidos en la OMC contribuyeron a hacer más costosas las respuestas más recalcitrantemente proteccionistas después de la crisis internacional de 2008 (OMC, 2012).

${ }^{14}$ Véase, por ejemplo, Matto and Subramanian (2009). En relación con este argumento resulta interesante advertir que las negociaciones de Doha acabaron empantanadas en torno a la agenda más tradicional de acceso a los mercados agrícolas y de manufacturas. La idea (ya esbozada durante la RU) de que una ampliación de la agenda acabaría creando oportunidades para un mayor abanico de concesiones cruzadas parece no haberse confirmado en la práctica. 
De acuerdo a esta interpretación esta disyunción entre la demanda y oferta de reglas estaría en la base de la pérdida de centralidad de la OMC como foro de negociación y su reemplazo por otros canales. En este contexto, una respuesta apropiada requeriría la "actualización" de esa agenda y el establecimiento de nuevos mecanismos y procedimientos para la toma de decisiones y la creación de reglas que permitan revitalizar el interés y viabilizar las negociaciones en el foro multilateral tomando nota del nuevo contexto.

\section{LOS LIMITES DE LA REFORMA INSTITUCIONAL}

En los últimos años se han lanzado varias propuestas de reforma de los mecanismos y procedimientos para la toma de decisiones y la creación de reglas en la OMC. Su propósito ha sido el de revitalizar el papel de la organización, adaptando los procedimientos a las nuevas condiciones en que opera el régimen. La mayoría de estas propuestas, sin embargo, no apunta a cuestiones formales de procedimiento sino que aspira a dinamizar el funcionamiento régimen modificando el status quo. En efecto, la mayoría de las propuestas parte implícita o explícitamente del reconocimiento de dos hechos. El primero es que los intereses de los distintos participantes se han vuelto crecientemente diferenciados. El segundo es que la tradicional combinación de procedimientos formales (la regla del consenso) y ejercicio del poder que funcionó aceptablemente durante las primeras décadas que siguieron al establecimiento del GATT han agotado su eficacia. Las propuestas se han hecho en general fuera del ámbito formal de la OMC y pueden resumirse en tres innovaciones principales, a saber: a) el abandono del principio de single undertaking, b) la adopción de nuevas modalidades de acuerdos y c) la modificación del proceso de toma de decisiones.

La cláusula de single undertaking fue adoptada en la RU con base en dos justificaciones. La primera fue incorporar un mecanismo que asegurara que cualquier acuerdo que eventualmente se alcanzara reflejara de manera más equilibrada los intereses de todos los miembros. La segunda fue ampliar el rango de concesiones y transacciones posibles, incorporando distintas áreas temáticas bajo el paraguas de una negociación y un acuerdo final únicos. Según sus promotores, al permitir concesiones cruzadas en temas diferentes el single undertaking haría posible balancear intereses en el contexto de una agenda más diversificada, ampliar los sectores involucrados, movilizar nuevos intereses y multiplicar el número de transacciones posibles. En los hechos, sin embargo, la cláusula fue instrumental para concluir las negociaciones de la RU no obstante las resistencias al paquete final por parte de varios de los participantes.

En efecto, como ya señalamos el riesgo de perder las concesiones obtenidas en negociaciones previas fue un poderoso incentivo para que todos los participantes de la RU suscribieran el Acta de Marrakesh que dio nacimiento a la OMC. Este resultado puede interpretarse recurriendo a lo que Grueber (2000) 
denomina "poder de avanzar solo" (go-it-alone-power). Según este mecanismo los "perdedores" en una negociación internacional institucionalizada podrían allanarse a las demandas de los "ganadores" no porque éstos apliquen un "poder coercitivo" o compensen su adhesión con "pagos laterales", sino porque saben que los "ganadores" están en una posición tal que pueden seguir adelante sin ellos. Esta imposibilidad de sostener el status quo podría inducir a los "perdedores" a cooperar (participando del acuerdo) aun cuando el resultado de esa cooperación no mejore su situación en relación al status quo (es decir, no sea Pareto-superior). En efecto, en las condiciones descritas la opción preferida de los "perdedores" (el status quo) simplemente no estaría más disponible como alternativa. ${ }^{15}$

La cláusula de single undertaking fue incorporada a la Ronda de Doha con los mismos propósitos declarados que en la RU, pero en un contexto de cambios significativos en el balance de poder y en la distribución de las capacidades de veto. El resultado fue no sólo la imposibilidad de arribar a acuerdos parciales, sino el bloqueo de la posibilidad de alcanzar un acuerdo global. En otras palabras, el papel que el principio de single undertaking desempeñó en el cierre de la RU simplemente no está disponible en la Ronda de Doha: en las condiciones actuales los "miembros recalcitrantes" aún tienen la opción del status quo multilateral. ${ }^{16}$

El abandono de la cláusula de single undertaking permitiría realizar acuerdos parciales dentro de la $\mathrm{OMC}$ en temas en los que los miembros están dispuestos a realizar transacciones auto-contenidas. Esto implicaría ir en dirección contraria a las razones que en su momento se esgrimieron para adoptar el principio, a saber: ampliar el espectro de transacciones posibles y vincular diferentes temas en los que existen intereses heterogéneos a través de un esquema de intercambios cruzados. En la práctica, el abandono del principio de single undertaking cristalizaría la "disfuncionalidad" entre la agenda de negociación multilateral y las llamadas "demandas funcionales del comercio internacional del siglo XXI". En efecto, el abandono del principio implicaría el reconocimiento formal de la creciente dificultad para negociar acuerdos que tengan una membresía efectivamente multilateral. La ventaja de este escenario sería la posibilidad de mantener acuerdos entre pocos dentro de los marcos del régimen multilateral, algo que de hecho ya existe: tanto los acuerdos plurilaterales como los acuerdos preferenciales son compatibles con la normativa multilateral bajo ciertas condiciones. Sin embargo, la experiencia de las últimas tres décadas ya mostró la naturaleza del dilema: por un lado, cuando estas condicio-

\footnotetext{
${ }^{15}$ Para una presentación del concepto de go-it-alone-power véase Grueber (2000) (pp. 7-8).

${ }^{16}$ Naturalmente la explotación del "poder de avanzar solo" a través de otras vías (como los acuerdos preferenciales) amenaza con relegar al régimen multilateral a una creciente marginalidad. Por lo tanto, el status quo multilateral actual no constituye un estado de equilibrio.
} 
nes son muy restrictivas la existencia de "válvulas de escape" no resuelve las tensiones; por el otro, cuando esas condiciones son laxas o ambiguas no hay incentivos para disciplinar su utilización. ${ }^{17}$

Una propuesta complementaria ha sido la de extender el uso de los acuerdos plurilaterales como modalidad de negociación. Los acuerdos plurilaterales datan de la época del GATT y tuvieron su apogeo con los "códigos" de participación voluntaria de la Ronda Tokio. Estos "códigos" cubrían distintos compromisos y disciplinas y establecían derechos y obligaciones sólo para los miembros que los hubieran suscrito. Como parte de los acuerdos de la RU todos los "códigos" (convenientemente actualizados) se hicieron universales y obligatorios, con excepción de cuatro Acuerdos Plurilaterales que se incorporaron al Anexo IV del Acuerdo de la OMC. De esos cuatro acuerdos plurilaterales sólo dos (comercio de aeronaves civiles y compras públicas) se encuentran actualmente vigentes.

La negociación de acuerdos que no involucren a todos los miembros (pero que no constituyen Acuerdos Plurilaterales con las características de los dos incluidos en el Anexo IV) volvió a repetirse en ocasión de la conclusión de los protocolos sobre telecomunicaciones y servicios financieros que quedaron pendientes de la RU y, posteriormente, en las negociaciones que llevaron a la suscripción del Acuerdo sobre Tecnologías de la Información (ITA) en 1996. En este último acuerdo un grupo de miembros (cuyo comercio representaba bastante más del $80 \%$ del comercio mundial de los productos cubiertos) decidió eliminar los aranceles y otros derechos o cargas sobre ese comercio. El lanzamiento de las negociaciones del ITA requirió del consenso de todos los miembros de la OMC (al igual que lo requeriría la conclusión de nuevos Acuerdos Plurilaterales), así como la aplicación de las concesiones negociadas sobre una base no-discriminatoria (a diferencia de lo que ocurría con los "códigos" de la Ronda Tokio o de lo que ocurre actualmente con los Acuerdos Plurilaterales del Anexo IV).

Los acuerdos plurilaterales no son per se inconsistentes con la cláusula del single undertaking, ya que un acuerdo negociado al amparo de esa cláusula podría incluir entendimientos entre sólo algunos miembros, tal como de hecho

${ }^{17}$ Un obstáculo clave para el abandono del principio de single undertaking es la exigencia de consenso entre todos los miembros. Tal como ocurrió con el reciente acuerdo sobre facilitación del comercio, también es posible implementar un acuerdo parcial que altere los derechos y obligaciones de los miembros a través de una enmienda del Anexo 1A (GATT 1994) del Acuerdo de la OMC. Esta enmienda, sin embargo, debe realizarse conforme lo establecido en el Artículo X del Acuerdo, que exige su ratificación por dos tercios de los miembros. Lo que es más importante, el nuevo acuerdo generará obligaciones sólo para los miembros que lo ratifiquen, quienes deberán implementarlo bajo el principio de nación más favorecida (es decir, extendiendo los beneficios a todos los miembros de la OMC) (South Center, 2014). Los obstáculos para extender este procedimiento a otras áreas son evidentes. 
ocurrió durante la RU. En realidad, la barrera más significativa parecería ser la exigencia de que todos los miembros otorguen su consentimiento para que se negocien nuevos acuerdos plurilaterales que puedan incorporarse al Anexo IV. Tal como ocurrió con el ITA, difícilmente ese consentimiento se lograría si no se extendieran al conjunto de los miembros sobre una base de nación más favorecida las concesiones que eventualmente se intercambien los participantes. Esta restricción operaría, en la práctica, como un incentivo para el free-riding. ${ }^{18}$

Otra propuesta de cambio en los procedimientos es la adopción de un enfoque de "masa crítica" con el objetivo de dinamizar y hacer más eficiente el proceso decisorio en la OMC, desalentar soluciones regionales a temas que pueden tratarse más eficazmente a nivel multilateral y permitir una diferenciación más efectiva de los derechos y obligaciones de un conjunto de países heterogéneo (Low, 2011, p 12). ${ }^{19}$ La aplicación de este enfoque requeriría resolver varios problemas sustantivos, el primero de los cuáles sería decidir bajo qué condiciones el enfoque sería aplicable. Esto implicaría responder preguntas tales como: ¿cuál es la extensión del apoyo que debería tener una propuesta para ameritar su tratamiento bajo el enfoque de "masa crítica"?; ¿cuánta justificación sustantiva acerca de las razones para recurrir a ese enfoque sería necesaria?; ¿el enfoque se limitaría a áreas actualmente cubiertas por las regulaciones de la OMC o se extendería a nuevos temas?. Por otra parte, también sería necesario establecer si el lanzamiento de negociaciones bajo la modalidad de la "masa crítica" requeriría del consenso de toda la membresía y si la aplicación de sus resultados se haría sobre una base discriminatoria (alcanzando sólo a los miembros participantes) o se extendería a toda la membresía de la OMC.

Dado que el requisito del consenso para lanzar nuevas negociaciones es la regla actualmente vigente en la $\mathrm{OMC}$, una aplicación efectiva del principio de "masa crítica" requeriría su flexibilización. Sin embargo, una flexibilización plantearía problemas de legitimidad y riesgos para la coherencia sistémica a menos que se acordaran reglas claras para la apertura de negociaciones cuyo cumplimiento estuviera sujeto a jurisdicción internacional. Low (2011) señala que aún cuando no se requiriera consenso para iniciar negociaciones bajo la modalidad de la "masa crítica", ese requisito sería inevitable al momento de adoptar el acuerdo negociado. ${ }^{20}$

${ }^{18}$ Rodríguez Mendoza (2011) propone la figura de "Acuerdos Plurilaterales-Plus" que extiendan las concesiones intercambiadas sobre una base de nación más favorecida. Esta nueva figura eludiría el requisito del consenso para el lanzamiento de las negociaciones, siempre y cuando éstas abordaran temas nuevos que no implicasen modificaciones en las disciplinas ya acordadas en la OMC.

${ }^{19}$ Gallaher and Stoler (2010) habían analizado en detalle los problemas de aplicar un enfoque de "masa crítica" a las negociaciones sobre comercio de alimentos.

${ }^{20}$ Low (2011) propone que el requisito del consenso al momento de la adopción del acuerdo se haga a través de un voto a favor o en contra que no permita enmiendas al acuerdo, en una espe- 
Low (2011) también desestima el argumento del free riding como base para oponerse a la extensión de las concesiones negociadas sobre una base no-discriminatoria. Si la existencia de una "masa crítica" se define como el punto en el que un grupo de miembros entiende que el tema ha conseguido un apoyo suficiente como para ser susceptible de negociaciones que no incluyan la participación de los remisos, éstos deberían ser lo suficientemente "pequeños" como para no poner en riesgo su aplicación. Por lo tanto, no podrían considerarse propiamente free riders y no habría razones para excluirlos de las consecuencias del acuerdo. El propio autor sostiene que las inconsistencias "dinámicas" del enfoque de la masa crítica (los "pequeños" de hoy pueden no serlo en el futuro) podrían enfrentarse a través de mecanismos ad hoc, como un sistema de revisión periódica o de indicadores cuantitativos.

En síntesis, a pesar del ingenio que revelan muchas de las propuestas de reforma de los procedimientos para la toma de decisiones y la creación de reglas en el régimen multilateral, ninguna de ellas enfrenta el problema clave de la ausencia de incentivos suficientes para adoptar los nuevos mecanismos dadas las opciones disponibles del status quo multilateral (para unos) y del uso estratégico del regionalismo (para otros). En efecto, los problemas de eficacia del régimen multilateral como foro de negociación parecen responder a determinantes más fundamentales que el diseño institucional y se encuentran en la radical transformación de las condiciones contextuales en las que el régimen opera. La apelación a los beneficios derivados de la preservación del régimen multilateral como bien público difícilmente constituya un incentivo suficiente en un contexto de intereses más heterogéneos y de una estructura de poder más diversificada. No obstante, y como ya señalamos, el status quo multilateral como opción de largo plazo no constituye un escenario de equilibrio: la multiplicación de acuerdos preferenciales, particularmente de tipo Norte-Sur, y el lanzamiento de nuevas negociaciones entre países desarrollados inclina la balanza hacia las consecuencias previsibles del uso estratégico del regionalismo.

\section{LOS USOS ESTRATEGICOS DEL REGIONALISMO}

El aumento en el número de acuerdos preferenciales que tuvo lugar en las tres últimas décadas ha sido tomado como evidencia del creciente vigor del regionalismo. En efecto, desde el lanzamiento de la Ronda Uruguay (1986) el número de acuerdos preferenciales notificados al GATT y la OMC alcanzó un promedio de veintitrés por año, en comparación con una media de cuatro durante los primeros cuarenta años de existencia del GATT. Pero el inventario de acuerdos preferenciales notificados en las tres últimas décadas constituye un conjunto muy heterogéneo de instrumentos del que pueden extraerse pocas con-

cie de fast-track multilateral. 
clusiones de interés. En efecto, muchos de ellos (principalmente entre países en desarrollo) aportan pocas novedades y fueron implementados muy imperfectamente. Los restantes (principalmente acuerdos de tipo Norte-Sur) sí constituyen un subconjunto relevante, pero que la literatura sobre el "nuevo regionalismo" abordó primordialmente a partir de sus componentes discriminatorios poniendo el foco en los temas de acceso a los mercados (principalmente de bienes).

En efecto, la mayor parte de la literatura sobre el "nuevo regionalismo" procuró responder la pregunta de si los acuerdos regionales estimulaban u obstaculizaban la apertura no-discriminatoria (OMC, 2011). En los términos de Bhagwati $(1995,2008)$ se trataba de esclarecer si el regionalismo operaba como un obstáculo (stumbling block) o un pilar (stepping stone) del multilateralismo. A pesar de la abundante producción académica en torno a esta pregunta los resultados de los estudios no fueron concluyentes: tanto en el plano teórico como empírico el interrogante sobre la naturaleza del vínculo entre regionalismo y multilateralismo quedó sin respuesta. Esta falta de respuestas obedeció tanto a cuestiones de método como de sustancia. Desde el punto de vista metodológico los problemas surgieron como resultado de las diferentes formas de especificar los vínculos causales y del empleo de distintas técnicas de estimación. Desde un punto de vista sustantivo los estudios cuantitativos pusieron el foco sobre aquellas variables más susceptibles de medición y manipulación a través de técnicas econométricas (en particular la relación entre preferencias arancelarias y liberalización no-discriminatoria). Estas variables, sin embargo, reflejaban muy imperfectamente las novedades y las implicaciones sistémicas del "nuevo regionalismo". Así, la concentración de los estudios empíricos en temas de acceso a los mercados de bienes hizo a un lado aspectos clave del "nuevo regionalismo" como el surgimiento de nuevos actores dinámicos en este tipo de acuerdos y la mayor cobertura regulatoria de los acuerdos negociados (especialmente los de tipo Norte-Sur) (Bouzas, 2007).

En efecto, uno de los rasgos clave del "nuevo regionalismo" (más que el aspecto meramente cuantitativo) fue la emergencia de un nuevo tipo de acuerdos comerciales recíprocos entre países en desarrollo y países desarrollados. La diplomacia comercial norteamericana, que hasta ese momento había concentrado sus energías en las negociaciones multilaterales, fue un actor central de este renovado auge del regionalismo. El primer antecedente de este giro fue el acuerdo de libre comercio con Canadá, rápidamente seguido por el Tratado de Libre Comercio de América del Norte (TLCAN) y, posteriormente, por una sucesión de acuerdos preferenciales (Chile, Australia, Nueva Zelanda, Jordania, Singapur los países centroamericanos y la República Dominicana, Colombia, Perú, etc.). El otro rasgo clave de esta nueva generación de acuerdos preferenciales fue su mayor cobertura temática: los compromisos típicos del "nuevo regionalismo" incluían no sólo la profundización de la eliminación de las barreras fronterizas al comercio de bienes, sino nuevas reglas en el campo de las 
medidas no-arancelarias, el "comercio de servicios", la protección de la propiedad intelectual, el acceso y el trato a la inversión, la política de competencia, las compras de gobierno, el medio ambiente y los estándares laborales, etc..

La inclusión de estos "nuevos temas" en los acuerdos típicos del "nuevo regionalismo" no puede desvincularse de las resistencias que el tratamiento de estos mismos temas enfrentaban en el ámbito multilateral. En efecto, como ya señalamos, la inclusión de los temas de protección de la propiedad intelectual, "comercio de servicios" y trato a la inversión como parte de las negociaciones de la RU fue un proceso impulsado por la diplomacia comercial norteamericana muy resistido que, hacia fines de la década del ochenta, tenía un destino incierto. Pero mientras estos "nuevos temas" no encontraban plena cabida en las negociaciones multilaterales la diplomacia comercial norteamericana los cristalizaba en acuerdos preferenciales con socios seleccionados. Incluso otros temas que se encontraban al margen de las negociaciones multilaterales (como los regímenes de compras gubernamentales, las políticas de competencia, o la relación entre comercio y estándares laborales y ambientales) se hicieron un lugar en los acuerdos preferenciales, creando un template que la diplomacia comercial norteamericana adoptó (y profundizó) en negociaciones posteriores.

El vínculo entre los obstáculos que enfrentaba la "agenda ofensiva" de Estados Unidos en el plano multilateral y los acuerdos preferenciales por ella promovidos no es apenas una conjetura. Por el contrario, fue expresamente señalado por la Oficina del Representante Comercial de Estados Unidos cuando sostuvo en un documento oficial: "al perseguir iniciativas comerciales múltiples Estados Unidos ha creado una 'competencia por la liberalización', lanzando nuevas negociaciones comerciales globales, apalancándose para promover nuevas negociaciones y resolver problemas, y estableciendo modelos de éxito en áreas como la propiedad intelectual, el comercio electrónico, el medio ambiente, el trabajo y la corrupción". ${ }^{21}$ No obstante estas evidencias sobre el carácter estratégico del "nuevo regionalismo" la producción académica de la época concentrada en los temas de acceso al mercado de bienes y en la dilucidación de la dicotomía stumbling block/stepping stone- las dejó pasar relativamente desapercibidas.

Hubieron de transcurrir más de dos décadas para que la literatura especializada ajustara el foco de sus preocupaciones hacia los temas de naturaleza regulatoria. El cambio tomó la forma de una nueva etiqueta (el "regionalismo del siglo XXI") que reemplazó la del "nuevo regionalismo". ${ }^{22}$ Sin embargo, los

${ }^{21}$ USTR (2005), pág. 1

${ }^{22}$ Es interesante notar que los elementos novedosos del nuevo enfoque tenían más que ver con el modo en que la literatura especializada se había aproximado al tema del regionalismo que con la existencia de cambios sustanciales en el contenido de este último. Como argumentamos más adelante, el "nuevo regionalismo" y el "regionalismo del Siglo XXI" tienen fuertes rasgos de 
elementos novedosas del nuevo enfoque tenían más que ver con el modo en que la literatura especializada se aproximaba al tema del regionalismo que con cambios sustanciales en el contenido de este último. Según Baldwin (2011) los acuerdos preferenciales característicos del "regionalismo del siglo XXI" serían el resultado de nuevas demandas funcionales planteadas por los cambios en la naturaleza del proceso productivo y la división internacional del trabajo, específicamente aquéllas asociadas con la profundización de la fragmentación internacional de los procesos productivos. Para Baldwin este "nuevo" tipo de comercio enfrenta barreras diferentes a las del pasado, las que plantean nuevas demandas funcionales de armonización en campos como las políticas de competencia, la eliminación de restricciones a los movimientos de capital, la mejora en la protección de la propiedad intelectual y el otorgamiento de garantías para la inversión. En un plano de mayor abstracción Antràs y Staiger (2008) sostienen que en un contexto de rápida expansión del proceso de off-shoring de insumos noestandarizados, las externalidades transfronterizas generadas por las políticas nacionales trascienden el efecto sobre los términos de intercambio convencionalmente empleado por la teoría del comercio internacional como justificativo de la existencia de acuerdos comerciales internacionales. ${ }^{23}$ En la medida que estas externalidades no serían susceptibles de administración a través de principios generales (como los de reciprocidad y no discriminación) que constituyen la base del régimen multilateral, los nuevos acuerdos preferenciales responderían a una demanda por instrumentos más idóneos para enfrentar los nuevos desafios de la cooperación internacional.

El "regionalismo del siglo XXI" y su agenda de disciplinas extendidas ya no se concentraría en las preferencias arancelarias sino en la armonización de políticas internas que crean barreras friccionales al comercio, aumentan el costo de hacer negocios en el exterior y limitan la movilidad y el acceso de las inversiones. Por consiguiente, en la medida que sus componentes discriminatorios serían menos relevantes el "regionalismo del siglo XXI" exhibiría un menor potencial de conflicto con las reglas del régimen multilateral. ${ }^{24}$ Esta visión

continuidad. Si la literatura especializada no destacó esos rasgos antes no fue porque éstos no existieran sino porque buena parte de la producción académica continuó anclada en los temas tradicionales del acceso al mercado de bienes.

${ }^{23}$ El principal argumento para explicar la existencia de acuerdos comerciales internacionales (una institución redundante para la teoría del comercio internacional convencional) es el control de las externalidades transfronterizas derivadas del incentivo de manipular los términos de intercambio. Véase Bagwell y Staiger (1999).

${ }^{24} \mathrm{Si}$ bien el $50 \%$ del comercio internacional tiene lugar entre países con acuerdos preferenciales vigentes, solo el $16 \%$ del comercio se hace efectivamente bajo preferencias y sólo el $1,8 \%$ se beneficia de márgenes de preferencia superiores al 10\%. Estas cifras corroborarían la idea de que las preferencias juegan un papel relativamente secundario en la negociación de acuerdos regionales. (OMC, 2012) 
benévola sobre los vínculos entre regionalismo y multilateralismo se complementa con el argumento de que los nuevos acuerdos incluyen disciplinas que tienen como propósito resolver problemas de coordinación que pueden enfrentarse más eficientemente entre un menor número de países que en el marco de un colectivo numeroso y heterogéneo como el de la OMC. En este sentido, los acuerdos regionales constituirían una nueva forma o "nivel" de gobernanza del sistema de comercio internacional complementario del régimen multilateral. Según esta interpretación la dicotomía stumbling block/stepping stone característica del "nuevo regionalismo" se habría diluido como resultado de la diferenciación de las agendas y de las demandas funcionales derivadas de procesos de integración más profunda.

Pero esta visión benévola sobre el vínculo entre el regionalismo y el régimen multilateral de comercio no excluye todos los riesgos de conflicto. En primer lugar, como el propio Baldwin (2011) señala no todos los países tienen la misma capacidad para impulsar la agenda de "intereses ofensivos" característica del "regionalismo del siglo XXI". Esto consolida las asimetrías propias del régimen multilateral y plantea un riesgo explícito de marginalización de una parte de la membresía. Si bien como analizamos en la primera sección el régimen multilateral siempre funcionó con base en una combinación de reglas y ejercicio del poder, el desplazamiento de la OMC como ámbito para la creación de nuevas reglas y la gobernanza del comercio internacional acentuaría las asimetrías en la capacidad de los Estados para crear y promover nuevas disciplinas. En un escenario de este tipo muchos países en desarrollo verían limitadas las opciones de actualización de sus marcos regulatorios quedando dependientes, en la práctica, de las modalidades que surjan del entramado de "intereses ofensivos" promovidos por los actores económicos más activos e influyentes en los países desarrollados.

Por otra parte, la proliferación de nuevas normas cristalizadas en acuerdos preferenciales minaría la universalidad de las reglas multilaterales y progresivamente las condenaría a un papel secundario. Del mismo modo, el mecanismo de solución de controversias de la OMC tendría jurisdicción sobre un conjunto de reglas y disciplinas crecientemente marginales. Baldwin (2011) ha sugerido que la multilateralización de las disciplinas negociadas en los acuerdos preferenciales podría ser una de las opciones para preservar los equilibrios propios del sistema multilateral. Pero para ello sería necesario que las disciplinas preferenciales guardaran cierta compatibilidad entre sí, las que luego podrían encuadrarse en el plano multilateral siguiendo esquemas como el del AGCS (donde cada Estado aplica diferentes políticas bajo una serie de preceptos comunes), o bien esquemas plurilaterales como el contratación pública. No obstante, este enfoque parte del supuesto de complementariedad entre las reglas de los distintos acuerdos regionales, algo que la evidencia empírica no confirma. 
Por último, aún en el caso de que las normas fueran plenamente complementarias, es muy probable que la coordinación entre ambos niveles de gobernanza requiriera de reglas explícitas para asegurar su consistencia a lo largo del tiempo. La evidencia disponible no permite ser optimista en esta materia. En efecto, desde los orígenes mismos del GATT las disciplinas que se aplican a la negociación de acuerdos preferenciales han sido extremadamente ambiguas. Esta ambigüedad ha permanecido inalterada desde la creación de la $\mathrm{OMC}$, excepto por algunos modestos avances registrados durante la RU y, posteriormente, durante la Ronda Doha. ${ }^{25} \mathrm{~A}$ juzgar por la evidencia, lo que los miembros parecen haber intentado preservar en el ámbito multilateral es la discrecionalidad para utilizar los acuerdos preferenciales como mejor cuadre a sus intereses, cualquiera sea la naturaleza de éstos.

En resumen, el dato más relevante de la explosión de regionalismo en las tres últimas décadas no es el número de acuerdos negociados sino su utilización estratégica por parte de actores clave que han visto fuertemente limitada su capacidad de modelar las reglas internacionales a través de los canales tradicionales que ofrecía la institucionalidad multilateral. En las nuevas condiciones del régimen multilateral el "poder de avanzar solo" (go-it-alone-power) ya no se refleja en la capacidad de influir de manera directa sobre su contenido sino en la construcción de regímenes regulatorios alternativos que eventualmente se conviertan en referencia para el resto de la comunidad internacional, anulando de facto la relevancia del status quo multilateral.

\section{LOS ACUERDOS MEGA-REGIONALES}

La explosión de regionalismo que tuvo lugar desde mediados de los ochenta tomó diversas formas que incluyeron la firma de acuerdos bilaterales e iniciativas "plurilaterales" que reunían grupos de países. Estas últimas fueron una característica del proceso de integración europeo desde sus orígenes y, por efecto demostración, se replicaron (con bastante menos éxito) en el caso de muchos países en desarrollo. Por el contrario, con pocas excepciones la diplomacia comercial norteamericana tomó un camino predominantemente bilateral. ${ }^{26}$ Este

${ }^{25}$ Como parte de los resultados de la RU los miembros del GATT acordaron un "Entendimiento relativo a la interpretación del Artículo XXIV del GATT 1994" que, no obstante, dejó numerosos puntos oscuros. Posteriormente, en el año 2006 el Consejo General acordó un "Mecanismo de Transparencia para los Acuerdos Regionales" que prevé el pronto anuncio de cualquier nuevo ACR y su notificación a la OMC siguiendo parámetros informativos pre-establecidos. Este último instrumento tiene un propósito puramente informativo y de transparencia, descartando explícitamente el ejercicio de cualquier tarea de evaluación por parte de la OMC.

${ }^{26}$ La excepción fue el US-CAFTA/DR entre Estados Unidos, los países del Mercado Común Centroamericano y la República Dominicana. Incluso el Tratado de Libre Comercio de América del Norte (TLCAN) fue una sumatoria de acuerdos bilaterales entre sus miembros. Las negociaciones para establecer un Área de Libre Comercio de las Américas nunca llegaron a buen 
énfasis en el bilateralismo, sin embargo, se complementó en los últimos años con el lanzamiento de negociaciones para alcanzar un Acuerdo Transpacífico (TPP) y un Acuerdo Transatlántico de Comercio e Inversión (TTIP). Si bien como veremos estas dos negociaciones tienen características diferentes, su conclusión exitosa tendría importantes implicaciones para la gobernanza del sistema internacional de comercio, reposicionando modelos hegemónicos de regulación del comercio. En ambos casos el propósito es alcanzar "acuerdos modelo" (start of the art agreements) que mejoren el acceso al mercado, armonicen prácticas regulatorias y, eventualmente, sirvan como referencia para futuros entendimientos más amplios. Sin embargo, las especificidades de las respectivas agendas de negociación implican que los desafíos que enfrenta cada uno de ellos, así como las perspectivas de que las negociaciones concluyan exitosamente, son sustancialmente diferentes.

\subsection{El Acuerdo Transpacífico}

El TPP tiene su antecedente en el Acuerdo Estratégico Transpacífico de Asociación Económica (P4) firmado por Brunei, Chile, Nueva Zelanda y Singapur en el año 2006. En 2009 se iniciaron negociaciones para extender ese acuerdo más allá de los cuatro miembros originales incorporando a Australia, Estados Unidos, Malasia, Perú y Vietnam en lo que se dio en llamar el Acuerdo Transpacífico. Posteriormente se unieron a las negociaciones Canadá, Japón y México, hasta alcanzar un total de doce países que representan una cuarta parte del comercio mundial. Varios de los participantes ya tienen acuerdos vigentes entre sí. Chile, por ejemplo, tiene acuerdos de libre comercio en vigor con todos miembros con excepción de Vietnam. Estados Unidos también tiene acuerdos vigentes con más de la mitad de los participantes, incluyendo Australia, Canadá, Chile, México, Nueva Zelanda, Perú y Singapur. México y Canadá, por su parte, tienen acuerdos con cinco de los doce participantes en las negociaciones del TPP. La mayor parte de estos acuerdos fueron heredados del período del "nuevo regionalismo" y responden a los (cronológicamente) distintos templates promovidos por la diplomacia comercial norteamericana. Dado este punto de partida resulta previsible que su objetivo principal sea la profundización y armonización de los resultados alcanzados en negociaciones bilaterales previas. De hecho, la principal novedad del TPP ha sido la incorporación de Japón a las negociaciones.

puerto y su lanzamiento fue más bien el resultado de las demandas planteadas por algunos países latinoamericanos (frente al hecho consumado del TLCAN) que una iniciativa norteamericana. Desde un punto de vista estratégico para la diplomacia comercial norteamericana las negociaciones bilaterales sucesivas siempre hicieron más sentido que un procesos plurilaterales. Véase Bouzas (2005). 
Las negociaciones del TPP cubren temas tradicionales incluidos en los acuerdos pre-existentes y algunas otras nuevas disciplinas y temáticas transversales. ${ }^{27}$ En materia de comercio de bienes el objetivo es eliminar los aranceles y las medidas no-arancelarias y adoptar un nomenclador arancelario único con un conjunto común de reglas de origen y un procedimiento de acumulación que facilite el comercio libre de aranceles de insumos, partes y productos intermedios entre los países miembros. La adopción de un régimen de acumulación de origen sería un logro importante del acuerdo, en tanto facilitaría la integración de cadenas productivas entre los países miembros. Esto requerirá, sin embargo, que el régimen de origen armonizado incorpore las principales sensibilidades y preocupaciones de los países miembros, y especialmente de Estados Unidos. Un tema sensible ha sido la aplicación del criterio de yarn forward para la industria textil y del vestido. ${ }^{28}$ En materia de acceso a los mercados también existen diferencias en lo que respecta al tratamiento de productos sensibles como los alimentos, el azúcar y los lácteos, los que han sido particularmente agudos entre Estados Unidos y Japón. ${ }^{29}$

Las negociaciones también abarcan disciplinas sobre medidas sanitarias y fitosanitarias y sobre barreras técnicas al comercio. En estos casos el objetivo es profundizar las reglas vigentes en la OMC a través de acuerdos sobre transparencia, regionalización, cooperación, pruebas de conformidad, equivalencias e internacionalización de estándares. Las negociaciones también aspiran a incorporar un capítulo sobre procedimientos aduaneros que asegure previsibilidad y transparencia y que acelere y facilite el comercio con el fin de estimular la integración de las empresas de la región a las cadenas internacionales de valor.

Además de la agenda vinculada al comercio de bienes las negociaciones del TPP abarcan "temas OMC+" como la provisión transfronteriza de servicios (incluyendo aquellos abastecidos por medios electrónicos), comercio electrónico, telecomunicaciones, compras gubernamentales, servicios financieros, protección de la propiedad intelectual y entrada temporaria de personas de ne-

${ }^{27}$ Para una síntesis véase: http://www.ustr.gov/about-us/press-office/fact-sheets/2011/november/ outlines-trans-pacific-partnership-agreement

${ }^{28}$ Según este criterio no recibirían trato preferencial los bienes terminados que hubiesen sido producidos con fibra proveniente de países de fuera de la región. Si bien para algunos países (como Vietnam) esta regla sería costosa, la experiencia indica que su generalización es el resultado más probable.

${ }^{29}$ En estos sectores sensibles los miembros del acuerdo presentan los mayores picos arancelarios: productos textiles e indumentaria en el caso de Australia, Perú y Nueva Zelanda; lácteos y derivados en Canadá y Estados Unidos; bebidas y tabaco en Vietnam, Singapur y Malasia; productos electrónicos en Brunei; y azúcar y derivados en México. Estos sectores han sido en general excluidos o sujetos a fuertes excepcionalidades en los acuerdos de libre comercio preexistentes. 
gocios. ${ }^{30}$ Asimismo, incluye "temas $\mathrm{OMCx}$ " como las políticas de competencia, tratamiento de las inversiones, condiciones de trabajo y medio ambiente. En todos estos campos las condiciones de acceso a los mercados son menos dependientes de medidas fronterizas que del entorno regulatorio doméstico, por lo que las negociaciones tienen un fuerte contenido de armonización regulatoria. En materia de acceso a mercados y trato preferencial, en varios de estos campos la diplomacia comercial norteamericana ha impulsado la metodología de "listas negativas", por la que sólo se excluyen de las reglas generales de trato aquellas actividades y prácticas explícitamente identificadas en las listas de excepciones.

Los "temas $\mathrm{OMC}+$ " han sido una fuente de diferencias en varias áreas en las que la diplomacia comercial norteamericana impulsa con vigor sus "intereses ofensivos". Uno de ellos es la adopción de estándares de protección de la propiedad intelectual más rigurosos que los establecidos en los acuerdos bilaterales pre-existentes o en el ADPIC (bajo el paraguas de la OMC). Algunas áreas de conflicto han sido la extensión del período de protección a las patentes medicinales y a los derechos de autor, la introducción de patentes sobre los procedimientos y métodos quirúrgicos y la adopción de mecanismos de control de la distribución de datos en internet. ${ }^{31}$ En todos estos casos la diplomacia comercial norteamericana ha seguido una lógica similar a la aplicada en los acuerdos bilaterales sucesivos: cada nueva generación de acuerdos ha profundizado y ampliado la protección en paralelo a la expansión del mercado y los servicios generados por las innovaciones técnicas.

En relación con las compras de gobierno, sólo Estados Unidos, Canadá, Japón y Singapur son signatarios del Acuerdo Plurilateral sobre Compras Gubernamentales de la OMC. Sin embargo, hay otros cinco países (México, Chile, Perú, Australia y Nueva Zelanda) que tienen tratados bilaterales de libre comercio con Estados Unidos que incluyen capítulos con compromisos equivalentes sobre compras de gobierno, como regla general siguiendo el template impulsado por la diplomacia comercial norteamericana. Esto deja a Brunei, Malasia y Vietnam como los únicos miembros actualmente al margen de esas disciplinas $\mathrm{y}$, por lo tanto, como quienes deberían implementar los mayores cambios como consecuencia de la eventual firma de un TPP. ${ }^{32}$ Entretanto, las perspectivas de que el alcance de los acuerdos en este campo se profundice incorporando compromisos efectivos para los niveles sub-nacionales de gobierno son remotas,

${ }^{30}$ Los "temas OMC+" son aquellos en los que se aspira lograr compromisos más profundos que los actualmente pactados en la OMC. Los "temas OMCx" son aquéllos que aún no forman parte de la agenda de negociaciones de la OMC.

${ }^{31}$ Véase Krist (2012) y Fergusson (2013).

${ }^{32}$ Malasia y Vietnam son observadores en el Acuerdo Plurilateral sobre Compras de Gobierno de la OMC. 
dado los obstáculos que seguirá representando para ello la organización federal de Estados Unidos.

Entre los "temas OMCx" un área tradicionalmente conflictiva ha sido la adopción de un mecanismo de controversias inversor-Estado. Sin embargo, entre los participantes en el TPP sólo Brunei, Nueva Zelanda y Vietnam no tienen ya vigentes acuerdos que regulan la cuestión. ${ }^{33}$ La diplomacia comercial norteamericana también promueve condiciones más restrictivas para la implementación de limitaciones transitorias al movimiento de capitales, todavía permitidas como acción excepcional en los capítulos referidos a trato a la inversión en algunos acuerdos bilaterales. Los capítulos sobre estándares laborales y ambientales también son materia de diferencias en la medida que la diplomacia comercial norteamericana insiste en la adopción de estándares armonizados y en el sometimiento de eventuales diferencias al mecanismo de solución de controversias, lo que eventualmente habilitaría la aplicación de sanciones comerciales por incumplimientos en estos capítulos.

Las negociaciones del TPP replican algunas de las asimetrías características de los acuerdos Norte-Sur típicos del "nuevo regionalismo", a saber: la poca atención a temas de "interés ofensivo" de los miembros en desarrollo. Tal es el caso, por ejemplo, de los subsidios internos (especial, pero no exclusivamente, en la agricultura), la legislación de defensa comercial o el movimiento de personas naturales prestadoras de servicios (el llamado "modo 4" de prestación de servicios en el AGCS). En estos campos no sólo no ha habido una profundización en el establecimiento de disciplinas en las sucesivas generaciones de acuerdos bilaterales, sino que en algunas áreas se ha registrado incluso una reversión de concesiones obtenidas en negociaciones previas. Tal ha sido el caso, por ejemplo, del mecanismo de paneles binacionales de revisión de las determinaciones sobre derechos compensatorios y antidumping que fuera acordado primero con Canadá y luego con México, pero que no fuera incorporado en ninguno de los posteriores acuerdos bilaterales firmados por Estados Unidos.

En síntesis, el TPP parece un buen ejemplo del uso estratégico del regionalismo en un contexto de parálisis de las negociaciones multilaterales. En el caso particular de esta negociación, además, no puede dejarse de lado los incentivos derivados de la competencia instalada entre Estados Unidos, China y Japón por influenciar en el área del Pacífico. Sus rasgos principales son consistentes con el template de los acuerdos asimétricos Norte-Sur que caracterizan la diplomacia comercial norteamericana desde el período del "nuevo regionalismo". La "plurilateralización" y profundización de los resultados plasmados en los acuerdos bilaterales pre-existentes modificaría el marco regulatorio del comercio regional

\footnotetext{
${ }^{33}$ Los acuerdos de libre comercio de los que es parte Estados Unidos incluyen como regla general un capítulo sobre tratamiento de la inversión que incorpora un mecanismo de solución de controversias inversor-Estado.
} 
en el área del Pacífico, creando incentivos para la incorporación de países que aún no tienen acuerdos bilaterales con Estados Unidos (como ya lo ha hecho con Malasia y Vietnam). Si bien las negociaciones del TPP han evidenciado conflictos de intereses en varias áreas, la existencia de una base común en un buen número de participantes y el carácter asimétrico de las negociaciones refuerza las perspectivas de un acuerdo. Las mayores reservas se relacionan con la participación de economías desarrolladas (como Japón) con las que Estados Unidos no ha conseguido aún alcanzar acuerdos de libre comercio. En estos casos la naturaleza de los conflictos parece ser más asimilable a aquéllos que surgen en las negociaciones del Acuerdo Transatlántico de Comercio e Inversión (TTIP).

\subsection{El Acuerdo Transatlántico de Comercio e Inversión}

E1 TTIP es una negociación más reciente que la del TPP pero tiene una historia más larga de antecedentes y propuestas para la creación de un área de libre comercio impulsada por grupos de interés y think tanks de la comunidad transatlántica. Estas propuestas cobraron renovado vigor con la decreciente capacidad de la "alianza atlántica" de operar como un dínamo de la función negociadora de la OMC. A diferencia del TPP las negociaciones del TTIP no responden al patrón típico de los acuerdos asimétricos Norte-Sur sino que incluyen una agenda y enfrenta las restricciones propias de negociaciones entre países desarrollados en las que los conflictos quedan anclados en grupos de interés bien establecidos y regímenes regulatorios y preferencias sociales divergentes. $^{34}$

Un acuerdo de libre comercio entre Estados Unidos y la Unión Europea constituiría una referencia clave para otros regímenes regionales y para el propio régimen de comercio multilateral. No obstante las modificaciones experimentadas en el escenario internacional que fueron resumidas en la primera sección de este trabajo, la reconstrucción de un consenso básico entre estos dos actores clave del régimen internacional de comercio constituiría un hito difícil de ignorar. Sin embargo, el impacto potencial de un acuerdo de libre comercio transatlántico es tan significativo como los propios obstáculos para concluirlo. ${ }^{35}$

El grupo de alto nivel que elaboró el documento que fue utilizado como disparador de las negociaciones organizó la agenda del TTIP alrededor de tres pilares, a saber: 1) el acceso al mercado de bienes y servicios, inversiones y

${ }^{34}$ Según Steinberg (2013) el catalizador de esta negociación es eminentemente geopolítico, a saber: la recuperación del liderazgo y la influencia en el escenario internacional tras la irrupción de las llamadas "poderes emergentes".

${ }^{35}$ El comercio recíproco de bienes entre la UE y Estados Unidos representa el 16\% del comercio mundial y las inversiones transatlánticas constituyen una fracción significativa de las inversiones globales. 
contratación pública; 2) la cooperación/convergencia regulatoria; y 3) otras disciplinas misceláneas como el comercio de materias primas y energía, las empresas estatales, la extensión de la protección de la propiedad intelectual, etc. ${ }^{36}$ En materia de acceso a los mercados de bienes el núcleo de la negociación reside en la liberalización del universo de bienes que permanece protegido después de seis décadas de negociaciones en el GATT. Si bien en la actualidad el $70 \%$ del comercio bilateral ya tiene lugar libre de aranceles existen picos importantes, entre otros, en sectores como lácteos y alimentos (donde los aranceles específicos y ad valorem exceden el $100 \%$ ) y productos textiles (OMC, 2014). En efecto, la protección remanente constituye el corazón de las sensibilidades de cada una de las partes.

Vinculado al acceso a los mercados, el tema de los subsidios internos ha sido tradicionalmente una fuente de conflicto en áreas como la agricultura, la energía y la producción de aeronaves. Ambas partes han sido renuentes a acordar disciplinas para la aplicación de subsidios internos tanto en las negociaciones multilaterales como en los acuerdos comerciales preferenciales que han suscrito con terceros. En particular, los subsidios a la agricultura han sido un tema de conflicto tradicional entre Estados Unidos y la Unión Europea. Estas diferencias explican que el tema de los subsidios no haya sido incluido en los mandatos de negociación del TTIP.

En materia de servicios las negociaciones presentan objetivos ambiciosos y áreas conflictivas en temas como el transporte de aviación civil, los servicios profesionales, financieros y audiovisuales, y el transporte marítimo ${ }^{37}$. Si bien las listas de ofertas intercambiadas no han tomado estado público, existen varias dificultades para negociar mejoras en el acceso a los mercados en actividades sensibles. Un caso particularmente conflictivo es el de los servicios audiovisuales por cuanto constituye un objetivo prioritario de la diplomacia comercial norteamericana, a la vez que es una fuente particular de sensibilidad defensivas por el lado europeo. ${ }^{38}$ También resultan conflictivas las negociaciones de servicios financieros debido a las diferentes estrategias regulatorias de cada una de las partes. Mientras que la propuesta de la UE implica crear nuevas normas regulatorias comunes en un contexto post-crisis ${ }^{39}$, la diplomacia comercial

${ }^{36}$ El Grupo de Alto nivel bilateral presentó su informe en febrero 2013, el que puede consultarse en: http://www.ustr.gov/about-us/press-office/reports-and-publications/2013/final-report-us-euhlwg

${ }^{37}$ En forma simultánea a las negociaciones del TTIP Estados Unidos y la UE se han embarcado en las negociaciones de un nuevo acuerdo plurilateral de servicios al margen de la OMC (Trade in International Services Agreement, TISA). Véase Marchetti y Roy (2013)

${ }^{38}$ La Comisión Europea no ha recibido un mandato para negociar en materia de servicios audiovisuales (Akhtar y Jones, 2013)

${ }^{39}$ Entre otros la búsqueda de la armonización regulatoria mediante el establecimiento de pautas comunes y el reaseguro del trato nacional, la incorporación de mecanismos de trabajo conjunto 
norteamericana procura dejar este tema fuera del TTIP o limitarlo a un acuerdo más acotado que replique lo acordado en otros tratados de libre comercio. ${ }^{40}$ Según Johnson y Schott (2013) la posición norteamericana sería partidaria de trasladar el tratamiento de las reformas regulatorias a otros foros como el G20. En el caso del transporte tanto la aviación civil como los servicios fluviales y marítimos son sensibles, especialmente para Estados Unidos, ya que la apertura del acceso requeriría la reforma de legislaciones domésticas de larga data, como la Jones Act (1920) que protege la marina mercante norteamericana. ${ }^{41}$

El capítulo sobre inversiones es otro tema problemático en la agenda bilateral, no obstante los altos estándares de protección que prevalecen en ambas partes. Tradicionalmente las disciplinas en materia de trato a las inversiones han intentado resolver problemas de acceso y de incertidumbre jurídica para los inversionistas de los países desarrollados con actividad en los países en desarro1lo. En el pasado, cuando se intentó extender este tipo de acuerdos a las economías desarrolladas se enfrentaron serios problemas derivados de la dificultad de establecer reglas generales de trato en áreas transversales que involucran sectores diversos. En el caso particular de las negociaciones del TTIP han surgido diferencias sobre las implicaciones de alterar el balance entre el derecho de los Estados a regular y la protección de los inversionistas, así como sobre la subordinación de las controversias a mecanismos jurisdiccionales o arbitrales que se encuentren fuera del Estado que aplica la medida. En un documento difundido en noviembre de 2013 la Comisión Europea subrayó dos prioridades en este campo (tanto en general como en las negociaciones del TTIP). La primera es mejorar las normas sobre protección de la inversión, en particular las relativas a la especificación de las situaciones en las que corresponde aplicar el concepto de "expropiación indirecta" y de las situaciones en las que el interés público prevalece por sobre las repercusiones económicas del accionar del Estado. Asimismo, se planteó la necesidad de precisar la definición del "trato justo y equitativo" de modo tal de reducir las posibilidades de interpretación de este principio por parte de los tribunales. El segundo núcleo de cuestiones destacado por el documento de la Comisión es la mejora en el funcionamiento del sistema de solución de controversias, previniendo demandas de carácter "frívolo" (a través de una obligación de pago de los costos totales procesales por parte de

para la implementación de estándares internacionales, la creación de un sistema de consultas mutual para la notificación de nuevas medidas financieras que puedan afectar a las partes involucradas en los acuerdos (Comisión Europea, 2013 b).

${ }^{40}$ Véase Fox (2014). El objetivo subyacente es que los acuerdos internacionales no condicionen los márgenes de maniobra del gobierno norteamericano para la implementación de las reformas que está impulsando dentro del sistema financiero doméstico.

${ }^{41}$ Estas sensibilidades son políticamente muy relevantes y podrían transformarse en un obstáculo a la aprobación de un acuerdo por parte del Congreso norteamericano, especialmente en ausencia de una autorización para negociar bajo el mecanismo de fast track. 
aquellos inversores que resulten perdedores en los arbitrajes) y dotando al sistema de mayor trasparencia a partir de la publicidad de los documentos de los casos y la participación de terceras partes interesadas. ${ }^{42}$

Finalmente, si bien la Unión Europea y Estados Unidos son signatarios del Acuerdo Plurilateral sobre Compras Públicas de la OMC, existen áreas de conflicto como la legislación norteamericana de Buy American y la dificultad para extender los compromisos adoptados a nivel federal hacia las unidades subnacionales de gobierno (una cuestión particularmente relevante en el caso de Estados Unidos). El capítulo de compras públicas del TTIP busca ampliar el alcance del mencionado acuerdo plurilateral, generando un acuerdo $\mathrm{OMC}+$ que cubra algunas de esas cuestiones sensibles y establezca nuevas reglas de trato nacional y acceso a mercados aplicables a las firmas de cada una de las partes. Sectores en los que las partes tienen mayor interés son el de construcciones, ingeniería, dispositivos y aparatos médicos y sanitarios, infraestructura y transporte público (USTR, 2014; Comisión Europea, 2013c).

No obstante la importancia de este primer pilar, un componente clave de las negociaciones son los obstáculos al acceso a los mercados que provienen de diferencias en los reglamentos internos en materia de sanidad, inocuidad, estándares, técnicos y pruebas de conformidad, y que constituyen el segundo pilar de las negociaciones. Es en torno a este capítulo sobre el que existen mayores expectativas potenciales en relación al impacto de un acuerdo. En efecto, un acuerdo en estos campos no sólo afectaría los flujos de comercio bilateral sino que podría constituir un marco de referencia inevitable para otras partes. Las alternativas para avanzar en la cooperación regulatoria van desde el reconocimiento mutuo de las reglas nacionales hasta la adopción de estándares armonizados y la convergencia de las practicas regulatorias (Comisión Europea, 2013; Schlosser y Bull, 2013). La primera de las opciones implica que las empresas deberían cumplir con las normas nacionales de una de las partes para que sus bienes pudieran ser comercializados sin más trámite en la otra. Más allá del problema implícito en la definición del estándar, la adopción de un criterio de reconocimiento mutuo supondría la utilización de bases de datos compartidas y/o el reconocimiento de procesos locales de evaluación. Sin embargo, la adopción de estándares armonizados no es un procedimiento menos complejo ya que requeriría no sólo la convergencia hacia un estándar común sino, también, la producción de nueva normativa que incluya desde la adopción de un etiquetado

\footnotetext{
${ }^{42}$ Acuerdos como el de libre comercio entre la Unión Europea y Canadá ya reflejan las modificaciones propuestas por la Comisión Europea. Para el TTIP la UE ha impulsado una consulta popular vía internet sobre este tema, hasta julio de 2014, buscando fortalecer su posición negociadora.
} 
común hasta la promulgación de nuevos códigos. ${ }^{43}$ En algunos campos la adopción de estándares internacionales podría resultar la opción más viable, pero es previsible que dichos estándares puedan establecerse en áreas relativamente poco conflictivas o donde el sector privado está dispuesto a avanzar. ${ }^{44} \mathrm{Si}$ bien este capítulo de las negociaciones ha recibido mucha atención por sus implicaciones potenciales, también enfrenta serios obstáculos provenientes de la heterogeneidad en las prácticas regulatorias que encuentran su origen tanto en preferencias sociales divergentes como en la influencia de intereses particulares. ${ }^{45}$

El tercer pilar de las negociaciones incluye una serie de temas que trascienden su potencial impacto en la agenda bilateral y cobran relevancia tanto por su capacidad para convertirse en fuente de referencia para el conjunto de la comunidad internacional, como por la lógica geopolítica que los orienta. Uno de estos temas es el de la transparencia y la predictibilidad en la gobernanza del comercio de productos primarios y energía, incluyendo el establecimiento de disciplinas para las empresas estatales. Si bien el comercio de energía entre Estados Unidos y la Unión Europea ha cobrado creciente relevancia como consecuencia de la revolución energética en el primero y los conflictos con Rusia en la segunda, la importancia de la cuestión relativa al comercio de productos primarios constituye una de las áreas más sensibles de la nueva agenda de negociación que algunos actores buscan impulsar en una instancia post-Doha de la OMC. ${ }^{46}$ En este punto la UE apunta a limitar las intervenciones del gobierno para el establecimiento de precios de tanto la energía como de los productos primarios,

${ }^{43}$ Los informes elaborados por grupos expertos (Comisión Europea, 2013; Schlosser y Bull, 2013) han identificado áreas potenciales de convergencia regulatoria, incluyendo dispositivos médicos, cosmética, productos farmacéuticos, químicos, pesticidas, tecnología de la comunicación, informática y automóviles. En algunos de estos sectores la co-existencia de regímenes regulatorios independientes plantea barreras de acceso al mercado no despreciables en un contexto de protección arancelaria prácticamente inexistente, como ocurre en la industria química.

${ }^{44}$ Esta opción se ha mencionado en el campo de las cuestiones ambientales y laborales, donde prima el reconocimiento de los Acuerdos Ambientales Multilaterales (MEAs en inglés) y de los estándares internacionales en materia laboral (Organización Internacional del Trabajo OIT). Sin embargo, en algunos campos subsisten importantes diferencias como se ha puesto de manifiesto en las negociaciones relativas a la mitigación de la emisión de gases de efecto invernadero.

${ }^{45}$ Estas diferencias se han expresado con vigor en áreas como las normas sanitarias y fitosanitarias y han llevado a las partes a recurrir al mecanismo de solución de controversias de la OMC en más de una ocasión-

${ }^{46}$ Un antecedente que sugiere las posibilidades de un acuerdo entre Estados Unidos y la UE en el área es la iniciativa de transparencia de industrias extractivas -Extractive Industry transparency Initiative (EITI). Ésta es una coalición mundial de gobiernos, empresas y la sociedad civil que trabajan en conjunto para mejorar la apertura y la gestión responsable de los ingresos procedentes de los recursos naturales. 
especialmente en los casos destinados a la exportación, algo sobre lo que Estados Unidos aún no ha publicado posiciones. En cambio las partes sí parecen converger en temas como la definición de disciplinas para empresas comercializadoras del Estado.

Finalmente, si bien en materia de protección de la propiedad intelectual existe un interés común en impulsar altos estándares de protección, antecedentes como el del Acuerdo Comercial de Lucha contra la Falsificación (AntiCounterfeiting Trade Agreement -ACTA) recomiendan ser cautos sobre las chances de arribar a un nuevo acuerdo ambicioso de propiedad intelectual. En efecto, el ACTA aún no logró dentro en la UE las ratificaciones necesarias para entrar en vigencia. Con el avance de las negociaciones las diferencias entre Estados Unidos y la UE en este capítulo se han centrado en cuestiones como el modo de abordaje de las indicaciones geográficas, el (especialmente en la provisión de servicios internet, principal nudo de la no ratificación del ACTA), y algunos aspectos vinculados a la protección de las patentes (plazos de protección, plazos de prueba, y vinculaciones entre productos patentados) (Athkar y Jones, 2013).

El síntesis, el TTIP recoge muchos de los temas propios del "nuevo regionalismo" y del "regionalismo del siglo XXI" también incorporados en la agenda del TPP. Sin embargo, a diferencia del TPP las áreas conflictivas difícilmente puedan resolverse con base en soluciones asimétricas características de los acuerdos Norte-Sur. En la medida que las diferencias remanentes obedecen a la existencia de intereses fuertemente organizados y supervivientes después de varias décadas de liberalización, así como a la expresión de diferentes patrones regulatorios en muchos casos asentados en preferencias sociales divergentes, las perspectivas de un acuerdo sustantivo parecerían enfrentar obstáculos importantes. Pero no hay duda que de concretarse el TTIP revitalizaría la alianza atlántica que fuera el eje de la gobernanza del sistema de comercio internacional en la posguerra, generando un mega-acuerdo regional que sería una referencia obligada para el resto de la comunidad internacional.

\section{A MODO DE CONCLUSION}

En este artículo argumentamos que existe una notable continuidad entre los incentivos y las características del "nuevo regionalismo" de las dos últimas décadas del siglo pasado y el "regionalismo del siglo XXI". Esta continuidad puede apreciarse mejor cuando se pone el foco en los aspectos sustantivos que comparten ambas modalidades, a saber: el tipo de disciplinas cubiertas y los actores clave que impulsaron su uso estratégico. El cambio en las condiciones bajo las que opera el régimen multilateral (analizadas en la primera sección de este artículo) también explican esta continuidad: tanto el "nuevo regionalismo" como el "regionalismo del siglo XXI" han sido respuestas a los bloqueos que 
enfrenta el régimen multilateral en el ejercicio de su función como foro de negociación.

Como se discutió en la segunda sección del trabajo la naturaleza de estos bloqueos hace improbable que éstos puedan removerse con reformas de procedimiento que alteren el status quo. El cambio en las condiciones en que el régimen opera no permite identificar los incentivos para que esa alteración resulte de la dinámica propia de la negociación multilateral. En este contexto, el uso estratégico del regionalismo (ya insinuado desde mediados de los ochenta) se ha intensificado con la emergencia del llamado "regionalismo del siglo XXI".

Como se analiza en la tercera sección del trabajo, si bien por la naturaleza de su agenda el "regionalismo del siglo XXI" ha sido caracterizado como más complementario con el régimen multilateral, el argumento no resulta convincente. Más bien por el contrario, el uso estratégico del regionalismo amenaza con reducir el rol y la relevancia de ese régimen como instrumento de gobernanza del comercio internacional, instalando modelos regulatorios que eventualmente se extiendan al resto de la comunidad internacional apoyados en el peso relativo de sus miembros. La falta de progreso en la definición de disciplinas que mejoren las perspectivas de consistencia entre el régimen multilateral y los acuerdos regionales de comercio constituye un indicador claro de la ausencia de incentivos para desarrollar mecanismos que promuevan la convergencia entre ambos instrumentos. En los hechos, la fragilidad de las disciplinas multilaterales que regulan el regionalismo ha preservado la discrecionalidad para que este última sea utilizado con propósitos diversos.

Las negociaciones del TTIP y del TPP, analizadas en la cuarta sección del artículo, son los ejemplos más recientes (y probablemente más ambiciosos) de dicha utilización estratégica del regionalismo. En ambos casos un acuerdo implicaría el establecimiento de un marco de referencia para el resto de los miembros de la comunidad internacional. Más allá de esta característica común, sin embargo, ambas negociaciones muestran diferencias sustanciales que influyen sobre sus perspectivas de materialización. Mientras que el TPP es asimilable a una negociación asimétrica tradicional de tipo Norte-Sur, el TTIP enfrenta los obstáculos derivados del conflicto entre intereses organizados supervivientes de varias décadas de liberalización y de patrones regulatorios que encuentran su fundamento tanto en intereses sectoriales consolidados como en preferencias sociales disímiles. La conclusión del TPP, por lo tanto, sería poco más que un paso en la extensión y plurilateralización del blueprint que distingue a los acuerdos preferenciales inspirados en las prioridades de negociación de la diplomacia comercial de Estados Unidos. Las perspectivas de conclusión exitosa del TTIP parecen, en cambio, menos halagüeñas: las sensibilidades y preferencias heterogéneas que caracterizan la relación entre Estados Unidos y la Unión Europea parecen un obstáculo difícil de sortear. No es en modo alguno evidente 
que el incentivo (y la probabilidad efectiva) de reconstruir un "liderazgo atlántico" como el que se conoció en el pasado sea un estímulo suficiente para superar esas barreras.

\section{REFERENCIAS BIBLIOGRÁFICAS}

AKHTAR, S. y JONES, V. (2013). "Proposed Transatlantic Trade and Investment Partnership (TTIP): In Brief". Congressional Research Service. 7-5700. Disponible en https://www.fas.org/sgp/crs/row/R43158.pdf [Último acceso enero 2014].

ANTRAS, P. y STAIGER, R. (2008). "Offshoring and the Role of Trade Agreements," Scholarly Articles 3374525, Harvard University Department of Economics.

BAGWELL, K. Y STAIGER, R (1999). "An Economic Theory of GATT", American Economic Review, 89 (1), pp, 215-248.

BALDWIN, R. (2006). Multilaterilising regionalism: Spaghetti bowls as building blocks on the path to global free trade. Cambridge, Mass. : National Bureau of Economic Research.

BALDWIN, R. (2011). "21st Century Regionalism: Filling the gap between 21st century trade and $20^{\text {th }}$ century trade rules". CEPR Policy Insight, No. 56.

BALDWIN, R. y EVENETT, S. (ed. 2011). Why World Leaders Must Resist the False Promise of Another Doha Delay. A VoxEu e-book, Londres: Centre for Economic Policy Research.

BALDWIN, R. y LOW, P. (2009). Multilateralizing regionalism. Challenges for the Global Trading System. World Trade Organization, Ginebra.

BARTON, J. et al. (2006). The evolution of the trade regime. Princenton: Princenton University Press.

BHAGWATI, J. (1995). "U.S. Trade Policy: The Infatuation with Free Trade Agreements" In Bhagwati, J. \& Krueger, A. eds., The Dangerous Drift to Preferential Trade Agreements, Washington, D.C., American Enterprise Institute for Public Policy Research.

BHAGWATI, J. (2008). Termites in the Trading System: How Preferential Agreements Undermine Free Trade. New York: Oxford University Press.

BOUZAS, R. (2005). "El "nuevo regionalismo" y el Area de Libre Comercio de las Américas: un enfoque menos indulgente", Revista de la CEPAL, Núm. 85, abril.

BOUZAS, R. (2007); Después de Doha: la agenda emergente del sistema de comercio internacional. Madrid: Marcial Pons.

COMISIÓN EUROPEA, (2013); "Transatlantic Trade and Investment Partnership The Regulatory Part" Disponible en http://trade.ec.europa.eu/doclib/docs/2013/july/ tradoc_151605.pdf [Úlúltimo acceso enero 2014].

COMISIÓN EUROPEA, (2013 b). "EU-US Transatlantic Trade and Investment Partnership (TTIP). Cooperation on financial services regulation". Disponible en http://trade.ec.europa.eu/doclib/docs/2014/january/tradoc_152101.pdf [Último acceso abril 2014].

COMISIÓN EUROPEA, (2013 c). "EU-US Transatlantic Trade and Investment Partnership (TTIP). Public Procurement. Initial EU position paper". Disponible 
en http://trade.ec.europa.eu/doclib/docs/2013/july/tradoc_151623.pdf [Último acceso abril 2014].

CROOME, J. (1998). Reshaping the World Trading System. A history of the Uruguay Round. Boston: Ed. Kluwer Law International.

FERGUSSON, I.; COOPER, W.; JURENAS, R.; WILLIAMS, B. (2013). "The Trans-Pacific Partnership Negotiations and Issues for Congress". Congressional Research Service. 7-5700. Disponible en http://www.fas.org/sgp/crs/row/R42694.pdf? utm_source $=$ The+TransPacific+Partnership+Would+Destroy+our+National+Sovereig nty\&utm_campaign=Trans-Pacific+Partnership\&utm_medium=email. [Último acceso enero 2014].

FOX, B. (2014). "EU and US aim for 2015 trade deal, exclude financial services", en EUobserver, 16/05/2014. Disponible en: http://euobserver.com/newws/124159 [Último acceso junio 2014].

GALLAGHER, P. and STOLER, A. (2010). "Viability of a Critical Mass Framework for Agricultural Trade Negotiations", RIRDC Publication No 10/025.

GRUBER, L. (2000). Ruling the World. Princeton: Princeton University Press.

HALE, T.; HELD, D.; YOUNG, K. (2013). Gridlock. Why global cooperation is falling when we need it most?. Cambridge: Polity Press.

JOHNSON, S. y SCHOTT, J. (2013). "Financial Services in Transatlantic Trade and Investment Partnership" Peterson Institute for International Economics. Policy Brief, $N^{\circ}$ PB13-26. Disponible en http://www. piie.com/publications/pb/pb13-26.pdf [Último acceso marzo 2014].

KRIST, W. (2012). Negotiations for a Trans-Pacific Partnership Agreement. Washington: Wilson Center. Program on America and the Global Economy.

LOW, P. (2011). "WTO decision-making for the future", Staff Working Paper ERSD2011-05.

MARCHETTI, J. and M. ROY (2013). "The TISA Initiative: an overview of market access issues", Staff Working Paper ESRD-2013-11, WTO.

MATTOO, A., and SUBRAMANIAN, A. (2009). "From Doha to the Next Bretton Woods: A New Multilateral Trade Agenda." Foreign Affairs 88(1): 15-26.

OMC, (2012) "Examen de Políticas Comerciales de Estados Unidos. Informe de la Secretaría". WT/TPR/S/275. Disponible en http://wto.org/spanish/tratop_s/tpr_s/ s275_s.zip [Último acceso marzo 2014].

OMC, (2013) "Examen de Políticas Comerciales de la Unión Europea. Informe de la Secretaría". WT/TPR/S/284. Disponible en http://wto.org/spanish/tratop_s/tpr_s/ s284_s.pdf [Último acceso marzo 2014].

OMC, (2014). "Aranceles de la Unión Europea". Disponible en http://tdf.wto.org/ TariffList.aspx [Último acceso marzo 2014].

ORGANIZACIÓN MUNDIAL DE COMERCIO (2012). Informe sobre el Comercio Mundial 2011, Ginebra: OMC.

OSSA, R. (2009). "A new trade theory of GATT/WTO negotiations", Staff Working Paper ERSD-2009-08, http://ssrn.com/abstract=1511712.

RODRÍGUEZ MENDOZA, M. (2011). "Towards "plurilateral plus" agreements" en Trade and Development Symposium. Perspectives on the Multilateral Trading System. Ginebra: ICTSD. 
ROSE, A. (2004). "Do we really know that the WTO Increases Trade?", American Economic Review, 94 (1): 98-114.

ROSALES, O. y HERREROS, S. (2014). "Mega-Regional trade negotiations: What is at stake for Latin Amercia" Inter-American Dialogue. Working Paper.

SCHLOSSER, A. y BULL, R. (2013). "Regulatory Cooperation in the TTIP". PENN Program on Regulation. Disponible en http://www.acus.gov/newsroom/administrative-fixblog/regulatory-cooperation-ttip [Último acceso marzo 2014].

SOUTH CENTER (2014). "WTO Negotiations on Trade Facilitation: Development Perspectives" South Bulletin, $\mathrm{n}^{\circ} 78$, Disponible en http://www.southcentre.int/wpcontent/uploads/2014/03/SB78_EN.pdf_ [Último acceso marzo 2014].

STEINBERG, F. (2013). "Negociaciones comerciales entre la UE y EEUU: ¿qué hay en juego?", Real Instituto Elcano, ARI 42/2013. Disponible en: http://www.realinstitutoelcano.org/wps/portal/rielcano/contenido?WCM_GLOBAL CONTEXT=/elcano/elcano_es/zonas_es/ari42-2013-steinbetg-negociacionescomerciales-ue-eeuu-ttip [Último acceso junio 2014].

SUBRAMANIAN, A. y WEI, S. (2007). "The WTO promotes trade strongly but unevenly", Journal of International Economics, 72 (1): 151-175.

TOMSZ, M., GOLDSTEIN, J. y RIVERS, D, (2007). "Do we really know that the WTO increases trade? Comment", American Economic Review 97 (5), 2005-2018.

USTR (2005). "Trade Policy Agenda 2005". Disponible en http://www.ustr.gov/ archive/assets/Document_Library/Reports_Publications/2005/2005_Trade_Policy_Ag enda/asset_upload_file820_7314.pdf [Último acceso enero 2014].

USTR, (2014). "U.S. Objectives, U.S. Benefits In the Transatlantic Trade and Investment Partnership: A Detailed View". Disponible en http://www.ustr.gov/about-us/pressoffice/press-releases/2014/March/US-Objectives-US-Benefits-In-the-TTIP-a-DetailedView [Último acceso marzo 2014].

WILKINSON, R. (2006). "The World Trade Organization and the governance of global trade", en WILKINSON, R.; RAITH, R.; HOWSE, R; y NICOLAIDIS, K.; "Global Trade Governance: the WTO at a crossroads", European Security and Global GovernanceEPC Working Paper Nro 26. Disponible en: http://www.sant.ox.ac.uk/people/ knicolaidis/epcworkingpaper26.pdf [Último acceso junio 2014].

WARWICK COMMISSION (2007). The Multilateral Trade Regime: Which Way Forward? the report of the first warwick commission. Coventry : University of Warwick. Disponible en http://www2.warwick.ac.uk/research/warwickcommission/worldtrade/ report/uw_warcomm_tradereport_07.pdf [Último acceso marzo 2014]. 
